\title{
ERRATUM
}

\section{Erratum to: Past and current trends in endoscopic diagnosis for early stage gastric cancer in Japan}

\author{
Kazuki Sumiyama ${ }^{1}$
}

Published online: 10 March 2017

(c) The International Gastric Cancer Association and The Japanese Gastric Cancer Association 2017

\section{Erratum to: Gastric Cancer (2017) 20 (Suppl 1): S20-S27 \\ DOI 10.1007/s10120-016-0659-4}

The author would like to correct the error in the publication of the original article. The corrected detail is given below for your reading:

The last sentence in the first paragraph beneath the heading "Detecting gastric cancer earlier" should read as "Recently, population-based cohort study performed in Japan revealed that gastric cancer mortality was reduced by $67 \%$ by endoscopic screening compared with radiographic screening [6]."

The online version of the original article can be found under doi:10.1007/s10120-016-0659-4.

\section{Kazuki Sumiyama}

kaz_sum@jikei.ac.jp

1 Department of Endoscopy, The Jikei University School of Medicine, 3-25-8 Nishi Shinbashi, Minato-ku,

Tokyo 105-8461, Japan 